Journal of Applied Pharmaceutical Science Vol. 5 (12), pp. 125-134, December, 2015

Available online at http://www.japsonline.com

DOI: $10.7324 / \mathrm{JAPS} .2015 .501222$

ISSN 2231-3354 (cc) BY-NC-SA

\title{
Development of Hydrophobic Carriers based tablets for Sustained Release of Verapamil
}

\author{
Sarada Anepu ${ }^{1 *}$, Lohithasu Duppala ${ }^{1}$, P. V. Pratyusha ${ }^{2}$ \\ ${ }^{1}$ A. U. College of Pharmaceutical Sciences, Andhra University, Visakhapatnam-530003, Andhra Pradesh, India. \\ ${ }^{2}$ Maharajah's College of Pharmacy, Phoolbaugh, Vizianagaram, Andhra Pradesh, India.
}

\section{ARTICLE INFO \\ Article history: \\ Received on: 13/09/2015 \\ Revised on: 02/10/2015 \\ Accepted on: 26/10/2015 \\ Available online: 27/12/2015}

\section{Key words:}

Bees wax, Carnauba wax, Melt granulation, PEG,

Stearic acid, Sustained

Release, Verapamil $\mathrm{HCl}$.

\begin{abstract}
The main aim of the study is to formulate sustained release matrix tablets of verapamil hydrochloride using hydrophobic carriers or meltable binders like stearic acid, carnauba wax and bees wax by melt granulation technique. The influence of a hydrophilic polymer like polyethylene glycol (PEG) was studied on the waxy matrices. Two grades of PEG (4000 and 6000) were used in the preparations. The granules were prepared and compressed into tablets and they are evaluated for their physicochemical properties and in vitro dissolution studies were done. The IR spectral analysis revealed that there are no interactions between drug and the polymers and are compatible with other. The release data were subjected to various release kinetic models and also compared with those of a commercial brand. The tablets prepared fulfilled all the official requirements according to the pharmacopeia. From the dissolution studies it was observed that carnauba wax acts a good retardant (more than $16 \mathrm{~h}$ ). Among the two grades of PEG used 4000 and 6000, PEG 6000 increases the drug release to a greater extent than PEG 4000. It was concluded that hydrophobic carriers which act as very good retardants of the drug and also PEG can be used as a channeling agent in waxy matrices to regulate the release of the drug.
\end{abstract}

\section{INTRODUCTION}

Sustained Release dosage forms are intended to release the drug at a predetermined rate by conserving a constant drug level for a specific period of time to minimize side effects. Sustained release dosage forms have made significant progress in terms of safety, efficacy and patient compliance. Preferably, a drug to attain the desired therapeutic action should rapidly get released at the site of action in optimum concentration, persist for desired time, spare other sites and then need to be eliminated from the site. The drug delivery in sustained release is substantially affected by the external environment (Chugh et al., 2012). Certain considerations to formulate a sustained-release formulation: 1) API should have short half life (yamada et al., 2001), 2) Absorption of the active compound should involve passive transport, 3) Pharmacological activity of the active

\footnotetext{
* Corresponding Author

Anepu Sarada, A. U. College of Pharmaceutical Sciences, Andhra

University, Visakhapatnam-530003, Andhra Pradesh, India.

saradaanepu2014@gmail.com
}

compound should be related to its blood levels, 4) The therapeutic window of the active drug should be wide (short half life drugs in particular) to avoid toxicity, 5) Should not be prone to extensive first pass metabolism. Verapamil belongs to class I (high solubility and high permeability) of the Biopharmaceutical Classification System (BCS). Only 10-20\% of the drug out of $90 \%$ of the dose absorbed from the digestive tract penetrates into circulatory system in unchanged form, remaining drug undergoes a first pass metabolism mainly in liver. Frequent administration results in an increased bioavailability due to the so called saturable first pass effect, a consequence of non linear pharmacokinetics of drug. Therefore development of a sustained release formulation helps in decreasing the frequency and overcoming this problem to some extent (Bhagwat et al., 2008). Verapamil hydrochloride is suitable candidate for designing sustained drug delivery system due to the short half-life and high frequency of administration (Vikas et al., 2013). The objective of the present work is the development and optimization of a sustained release formulation using hydrophobic carriers by melt granulation technique and looking out the effect of hydrophilic polymers on the developed formulation taking verapamil as the model drug. 
The development of formulations containing hydrophobic carriers will be attempted using melt granulation and the in vitro release of the drug from the matrix tablet is evaluated. The influence of PEG different grades (hydrophilic polymers) on the release of the drug is evaluated and different modules like polymer type (PEG suitable grade), drug to polymer ratio were examined and optimized. The granular blend is also evaluated for its flow properties by calculating the angle of repose, carr's index, hausner's ratio and the properties were compared with each excipient and the formulation having good flow properties is selected. In a similar fashion the tablets were evaluated for its hardness, friability, thickness, drug content to assess them as per IP. The kinetics was also studied by fitting into various equations which depict the release mechanism of the drug from the tablet and the best fit in equation was selected.

\section{MATERIALS AND METHODS}

\section{Materials}

Verapamil $\mathrm{HCl}$ was received as a gift sample from Ranbaxy Laboratories Ltd., India. Besswax (Finar Chemicals, Ahmadabad), carnauba wax, microcrystalline cellulose (Otto kemi, Mumbai) polyethyleneglycol 4000 (Yarrowchem, Mumbai),all other chemicals were analytical grades.

\section{Methods}

In the present study, formulation of matrix tablet using hydrophobic carriers like stearic acid, carnauba wax, bees wax is done by preparing granules by melt granulation technique (F1, F2, and F3).

\section{Preparation of granules by melt granulation technique}

Hot melt granulation technique was used to prepare the drug-wax matrix tablets. The required amount of hydrophobic carrier or the meltable binder or the waxy material was melted in a porcelain dish on a water bath maintained at a constant temperature as per their melting points. Verapamil $\mathrm{HCl}$ was gradually added to the molten wax with continuous stirring. The molten mixture was allowed to cool and solidify at room temperature.

Table 1: Formulation table designed only with hydrophobic carriers.

\begin{tabular}{lcccccc}
\hline Ingredients (mg/tablet) & F1 & F2 & F3 & F4 & F5 & F6 \\
\hline Drug & 90 & 90 & 90 & 90 & 90 & 90 \\
Stearic acid & 30 & - & - & 30 & - & - \\
Carnauba wax & - & 30 & - & - & 30 & - \\
Bees wax & - & - & 30 & - & - & 30 \\
Microcrystalline cellulose & - & - & - & 30 & 30 & 30 \\
Magnesium Stearate & 5 & 5 & 5 & 5 & 5 & 5 \\
Aerosil & 5 & 5 & 5 & 5 & 5 & 5 \\
\hline
\end{tabular}

The drug was present in its solid form within the molten mass. The solidified mass was pulverized in a mortar and sieved through a 16 \# screen. Finally, lubricated with glidants and the granules were ready for compression (Senthil et al., 2011). To increase the intactness of the tablet, the above formulation is modulated to some extent to develop new formulations by the addition of microcrystalline cellulose (F4, F5, and F6) (Durgacharan et al., 2008).

Polyethylene glycols was added as a channeling agent to the matrix tablet of verapamil $\mathrm{HCl}$ in combination with selected hydrophobic carriers like bees wax, carnauba wax, and stearic acid. Two different grades of PEG were selected like PEG 4000 and PEG 6000 to study their effect on sustaining the action of verapamil $\mathrm{HCl}$. The formulations were prepared using melt granulation technique as described above except the case of PEG addition. The PEG should be taken along with the hydrophobic carrier in the porcelain dish and melted on a water bath. The composition with respect to waxes combination was selected on the basis of trial preparation of tablets.

\section{Evaluation of blend Angle of Repose}

Angle of repose is the maximum angle possible between the surface of the pile of the powder /granules and the horizontal plane. The angle of repose is measured using fixed funnel method in which the material is poured through a funnel to form a cone. The tip of the funnel should be held close to the growing cone and slowly raised as the pile grows to minimize the impact of the falling particles. The coefficient of friction between the granular materials is equal to the tangent of the angles of the internal friction for the materials (Mobeen et al., 2015).

$$
\operatorname{Tan} \theta=\mathrm{h} / \mathrm{r}
$$

Where, $\theta=$ angle of repose,

$\mathrm{h}=$ height of granules above the flat surface,

$r=$ radius of the circle formed by the granule heap.

\section{Bulk Density and Tapped Density}

The granules were weighed and passed through a sieve \# 22 and poured into a $25 \mathrm{ml}$ measuring cylinder. The initial volume was noted. Bulk density is the ratio of the mass to its initial volume. Then it is tapped from a height of $2.5 \mathrm{~cm}$ at second intervals on to a hard surface. Tapping was continued until there is no change in the volume. Tapped density is the ratio of the mass to the final volume (Lohithasu et al., 2015).

Bulk Density $=$ Weight of the powder blend / Untapped Volume of the packing

Tapped Density $=$ Weight of the powder blend / Tapped Volume of the packing

\section{Carr's consolidation index}

Carr's index is an indication of the compressibility and flow ability of the powder. The smaller the Carr's index, the better are the flow properties.

Carr's index $=(1-$ bulk density / tapped density $) * 100$

\section{Hausner's Ratio}

Hausner's ratio $=$ Tapped Density $/$ Bulk Density A hausner's ratio of $<1.25$ indicates a powder that is free flowing whereas $>1.25$ indicates poor flow ability (Lohithasu et al., 2015). 
Table 2: Formulation table with incorporation of hydrophilic polymer (PEG 6000).

\begin{tabular}{|c|c|c|c|c|c|c|c|c|c|}
\hline Ingredients (mg/tablet) & $\mathbf{F 4 A}_{1}$ & $\mathbf{F 4 A _ { 2 }}$ & $\mathbf{F 4 A _ { 3 }}$ & $\mathbf{F 5 A}_{1}$ & $\mathrm{F5A}_{2}$ & $\mathrm{F5A}_{3}$ & $\mathbf{F 6 A}_{1}$ & $\mathbf{F 6 A}_{2}$ & $\mathbf{F 6 A}_{3}$ \\
\hline Drug & 90 & 90 & 90 & 90 & 90 & 90 & 90 & 90 & 90 \\
\hline Stearic acid & 30 & 30 & 30 & - & - & - & - & - & - \\
\hline Carnauba wax & - & - & - & 30 & 30 & 30 & - & - & - \\
\hline Bees wax & - & - & - & - & - & - & 30 & 30 & 30 \\
\hline PEG 6000 & 25 & 30 & 35 & 25 & 30 & 35 & 25 & 30 & 35 \\
\hline Microcrystalline cellulose & 25 & 30 & 15 & 25 & 30 & 15 & 25 & 30 & 15 \\
\hline Magnesium stearate & 5 & 5 & 5 & 5 & 5 & 5 & 5 & 5 & 5 \\
\hline Aerosil & 5 & 5 & 5 & 5 & 5 & 5 & 5 & 5 & 5 \\
\hline
\end{tabular}

Table 3: Third formulation table with incorporation of hydrophilic polymer (PEG 4000).

\begin{tabular}{|c|c|c|c|c|c|c|c|c|c|}
\hline Ingredients (mg/tablet) & $\mathbf{F}_{4} B_{1}$ & $\mathrm{~F}_{4} \mathrm{~B}_{2}$ & $\mathbf{F}_{4} \mathbf{B}_{3}$ & F5B $_{1}$ & F5B $_{2}$ & F5B $_{3}$ & F6B $_{1}$ & F6B $_{2}$ & F6B $_{3}$ \\
\hline Drug & 90 & 90 & 90 & 90 & 90 & 90 & 90 & 90 & 90 \\
\hline Stearic acid & 30 & 30 & 30 & - & - & - & - & - & - \\
\hline Carnauba wax & - & - & - & 30 & 30 & 30 & - & - & - \\
\hline Bees wax & - & - & - & - & - & - & 30 & 30 & 30 \\
\hline PEG 4000 & 25 & 30 & 35 & 25 & 30 & 35 & 25 & 30 & 35 \\
\hline Microcrystalline cellulose & 25 & 30 & 15 & 25 & 30 & 15 & 25 & 30 & 15 \\
\hline Magnesium stearate & 5 & 5 & 5 & 5 & 5 & 5 & 5 & 5 & 5 \\
\hline Aerosil & 5 & 5 & 5 & 5 & 5 & 5 & 5 & 5 & 5 \\
\hline
\end{tabular}

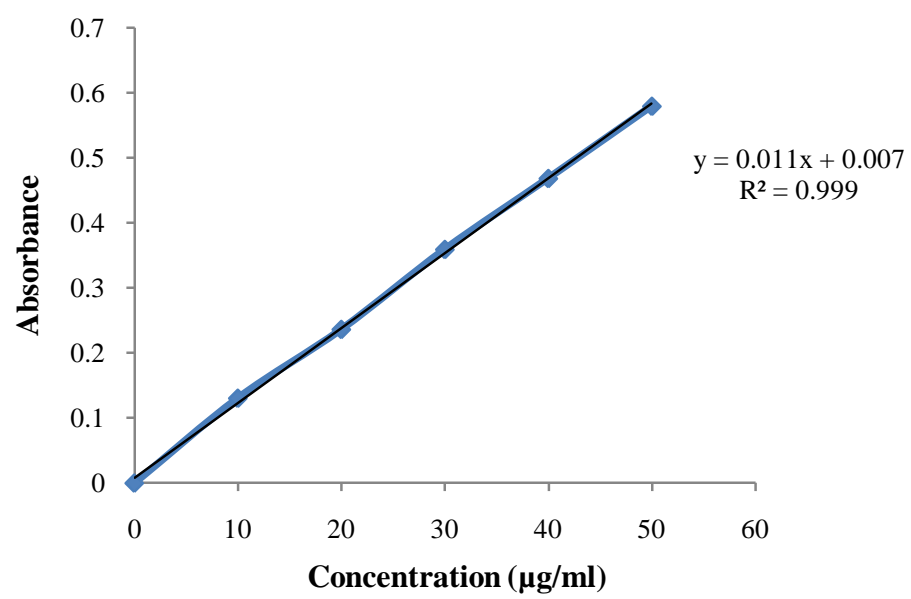

Fig. 1: Calibration curve for verapamil $\mathrm{HCl}$ in distilled water.

\section{EVALUATION OF TABLETS}

\section{Weight Variation test}

20 tablets from each formulation were selected in random and weighed using an electronic balance and mean and relative standard deviation of the weight were determined based on an official method as per IP.

\section{Hardness}

The diametrical crushing strength test was performed on 10 tablets from each formulation. 10 tablets were tested using a Monsanto hardness tester. It is expressed in $\mathrm{Kg} / \mathrm{cm}^{2}$. A hardness of $4 \mathrm{Kg} / \mathrm{cm}^{2}$ is considered to be a minimum for a satisfactory tablet.

\section{Friability test}

For each formulation, the friability of 20 tablets was determined using a Roche type friabilator. 20 tablets from each formulation were weighed and tested at a speed of $25 \mathrm{rpm}$ for 4 min. Acceptable if $0.5-1 \%$ of the tablet weight was lost. After removing of dusts, tablets were re-weighed and friability percentage was calculated using the following equation

$$
F(\%)=\frac{\left(W_{\text {initial }}\right)-\left(W_{\text {final }}\right)}{\left(W_{\text {initial }}\right)} \times 100
$$

\section{Drug Content}

Weigh accurately the powder equivalent to $100 \mathrm{mg}$ of verapamil hydrochloride and it was shaken with $150 \mathrm{ml}$ of $0.1 \mathrm{M}$ hydrochloric acid to produce $200 \mathrm{ml}$ volume. From this $10 \mathrm{ml}$ of the filtrate was collected and it was diluted to $100 \mathrm{ml}$ with distilled water and the absorbance was measured at $279 \mathrm{~nm}$ spectrophotometrically. Calculate the content of the verapamil hydrochloride taking 118 as the value of A (1\% $1 \mathrm{~cm}$ ) at the maximum at about $279 \mathrm{~nm}$. Three determinations were carried out for each batch. 


\section{Thickness}

Thickness was measured using a vernier caliper. Five tablets were selected in a random manner and their thickness is calculated. $\pm 5 \%$ may be allowed depending on the size of the tablet.

\section{Dissolution Studies}

Dissolution was carried out in paddle USP type II apparatus (TDT - 08L, Electro lab, Mumbai). It is generally performed at physiologically significant $\mathrm{pH} \mathrm{1.2,} 4.5$ and 6.8. Dissolution was performed in $900 \mathrm{ml}$ of $0.1 \mathrm{~N} \mathrm{HCl}$ maintained at $37 \pm 0.5{ }^{\circ} \mathrm{C}$ at an agitation speed of $50 \mathrm{rpm}$ for one hour in $0.1 \mathrm{~N}$ $\mathrm{HCl}$ and then it was performed in phosphate buffer $\mathrm{pH} 6.8$ for the remaining $11 \mathrm{~h} .5 \mathrm{ml}$ samples were withdrawn at regular time intervals such as $1,2,4,6,8,10,12 \mathrm{~h}$. Samples withdrawn are then filtered using whatman filter papers and then diluted sufficiently and were quantified spectrophotometrically at absorption $\lambda$ max of $279 \mathrm{~nm}$. Appropriate precautions were taken to minimize any errors while collecting the samples such as collection of the sample should be done from the center of the flask without touching the walls. An accumulative correction was made for removed samples in determining the total amount dissolved. Dissolutions runs were always performed in triplicates. The absorbance values were noted from which the concentrations were calculated using the

\section{Release Kinetics}

The mathematical models used to determine the kinetics of drug release from drug delivery systems. The quantitative analysis of the values obtained in dissolution/release rates is easier when mathematical formulae are used to describe the process. The mathematical modeling can ultimately help to optimize the design of a therapeutic device to yield information on the efficacy of various release models. The fundamental principle for evaluation of the kinetics of drug release was offered by Noyes and Whitney in 1897. Brunner and Nernst used Fick's law of diffusion to establish a relationship between the constant and the diffusion coefficient of the solute.

\section{Model Dependent Methods}

Model dependent methods are based on different mathematical functions, which describe the dissolution profile. Once a suitable function has been selected, the dissolution profiles are evaluated depending on the derived model parameters. The model dependent approaches included zero order, first order, Higuchi, Hixson-Crowell, Korsmeyer-Peppas, Baker-Lonsdale, Weibull, Hopfenberg, Gompertz and regression models.

\section{Zero-order model}

Drug dissolution from dosage forms that do not disaggregate and release the drug slowly can be represented by the equation:

$$
\mathrm{Q}_{0}-\mathrm{Q}_{\mathrm{t}}=\mathrm{K}_{0} \mathrm{t}
$$

Where, $Q_{t}$ is the amount of drug dissolved in time ' $t$ ',
$\mathrm{Q}_{0}$ is the initial amount of drug in the solution

$\mathrm{K}_{0}$ is the zero order release constant expressed in units of concentration/time.

To study the release kinetics, data obtained from in vitro drug release studies were plotted as cumulative amount of drug released versus time (Narasimhan et al., 1999)

Application: This relationship can be used to describe the drug dissolution of several types of modified release pharmaceutical dosage forms as in the case of some transdermal systems and as well as matrix tablets with low soluble drugs in coated forms, osmotic systems, etc.

\section{First order model}

This model has also been used to describe absorption and/or elimination of some drugs, although it is difficult to conceptualize this mechanism on a theoretical basis. The release of the drug which followed first order kinetics can be expressed by the equation:

$$
\mathrm{dC} / \mathrm{dt}=-\mathrm{Kc}
$$

Where, $K$ is first order rate constant expressed in units of time ${ }^{-1}$. The above equation can be expressed as:

$$
\log \mathrm{C}=\log \mathrm{C}_{0}-\mathrm{Kt} / 2.303
$$

Where, $\mathrm{C}_{0}$ is the initial concentration of drug, ' $\mathrm{k}$ ' is the first order rate constant, and ' $t$ ' is the time (Banker). The data obtained were plotted as log cumulative percentage of drug remaining $v s$. time which would yield a straight line with a slope of $-K / 2.303$. Application: This relationship can be used to describe the drug dissolution in pharmaceutical dosage forms such as those containing water-soluble drugs in porous matrices (Silvina et al., 2002).

\section{Higuchi Model}

The first example of a mathematical model aimed to describe drug release from a matrix system was proposed by Higuchi in 1961.

$$
\mathrm{Q}=\mathrm{K}_{\mathrm{H}} * \mathrm{t}^{1 / 2}
$$

The data obtained were plotted as cumulative percentage drug release versus square root of time (Higuchi et al.,1961) Application: This relationship can be used to describe the drug dissolution from several types of modified release pharmaceutical dosage forms, as in the case of some transdermal systems and matrix tablets with water soluble drugs (Grassi et al., 2005).

\section{Hixson-Crowell model}

Hixson and Crowell (1931) recognized that the particles regular area is proportional to the cube root of its volume. They derived the equation:

$$
\mathrm{Q}_{0}{ }^{1 / 3}-\mathrm{Q}_{\mathrm{t}}^{1 / 3}=\mathrm{k}_{\mathrm{hc}} \mathrm{t}
$$

Where, Qo is the initial amount of drug in the pharmaceutical dosage form,

$Q_{t}$ is the remaining amount of drug in the pharmaceutical dosage form at time ' $t$ '

$\mathrm{k}_{\mathrm{hc}}$ is a constant incorporating the surface volume relation. 
To study the release kinetics, data obtained from in vitro drug release studies were plotted as cube root of drug percentage remaining in matrix versus time. Application: This expression applies to pharmaceutical dosage form such as tablets, where the dissolution occurs in planes that are parallel to the drug surface if the tablet dimensions diminish proportionally, in such a manner that the initial geometrical form keeps constant all the time.

\section{Korsmeyer-Peppas model}

Korsmeyer Peppas developed a simple, semi-empiric model, (Korsmeyer et al., 1983) when diffusion is the main drug release mechanism. In this model drug release is exponentially related to the elapsed time $(\mathrm{t})$.

$$
\mathrm{Q}_{\mathrm{t}} / \mathrm{Q}_{\infty}=\mathrm{at}^{\mathrm{n}}
$$

Peppas used this ' $n$ ' value in order to characterize different release mechanisms. To the determination of the exponent ' $n$ ' the portion of the release curve where $\mathrm{Q}_{t} / \mathrm{Q}_{\infty}=0.6$ should only be used. This model is generally used to analyze the release of pharmaceutical and polymeric dosage forms, when the release mechanism is not well known or when more than one type of release phenomena could be involved (Ritger et al., 1987). The release exponent $\mathrm{n}=$ 1.0 for case-II mechanism, $\mathrm{n}=0.5$ for fickian diffusion controlled drug release, $\mathrm{n}$ value between 0.5 and 1.0 or anomalous release or non-fickian mechanism and $\mathrm{n}$ value is $>1.0$ for super case-II transport mechanism.

\section{RESULTS AND DISCUSSION}

\section{FTIR studies}

Drug excipients interactions were characterized by IR spectroscopy studies, the IR spectrum of $\mathrm{VH}$ (pure drug) and different combinations of excipients were studied and the resultant graphs were shown in Fig. 3 to Fig. 7.

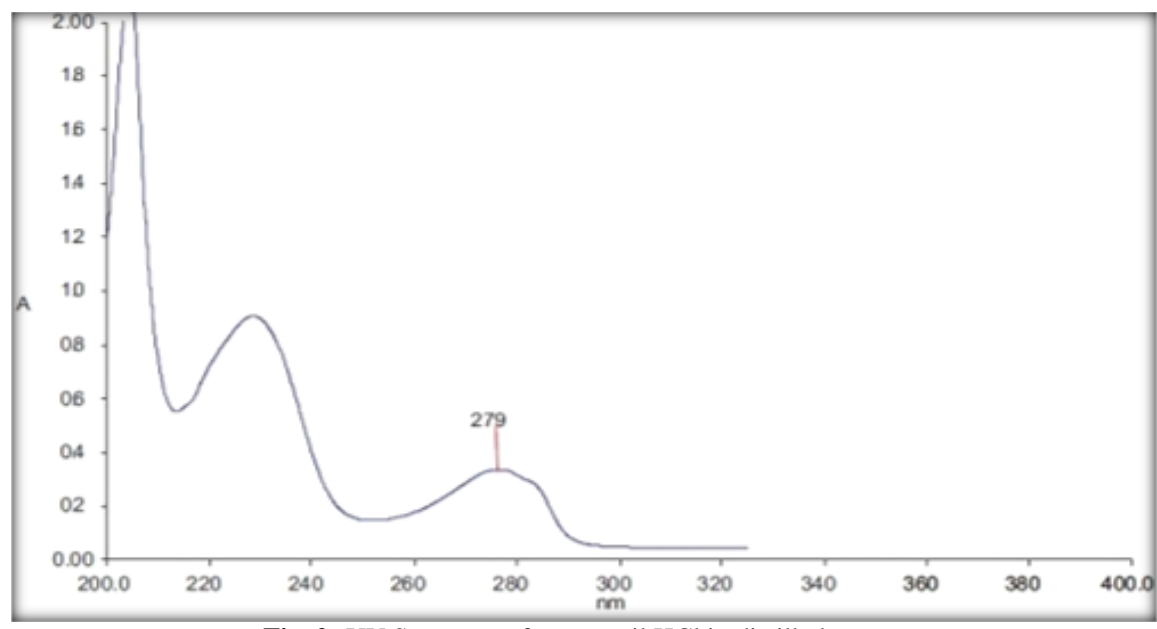

Fig. 2: UV Spectrum of verapamil $\mathrm{HCl}$ in distilled water.

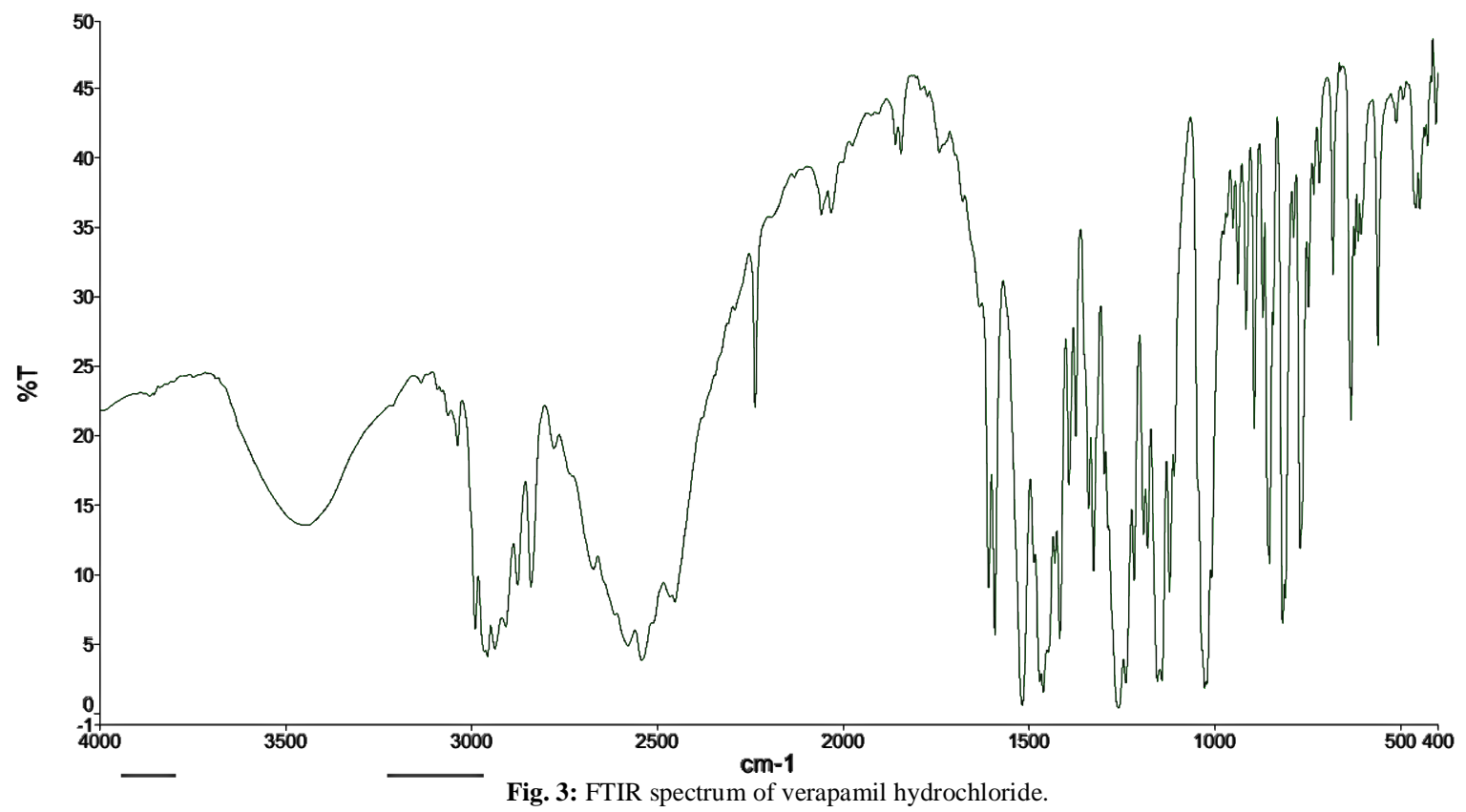




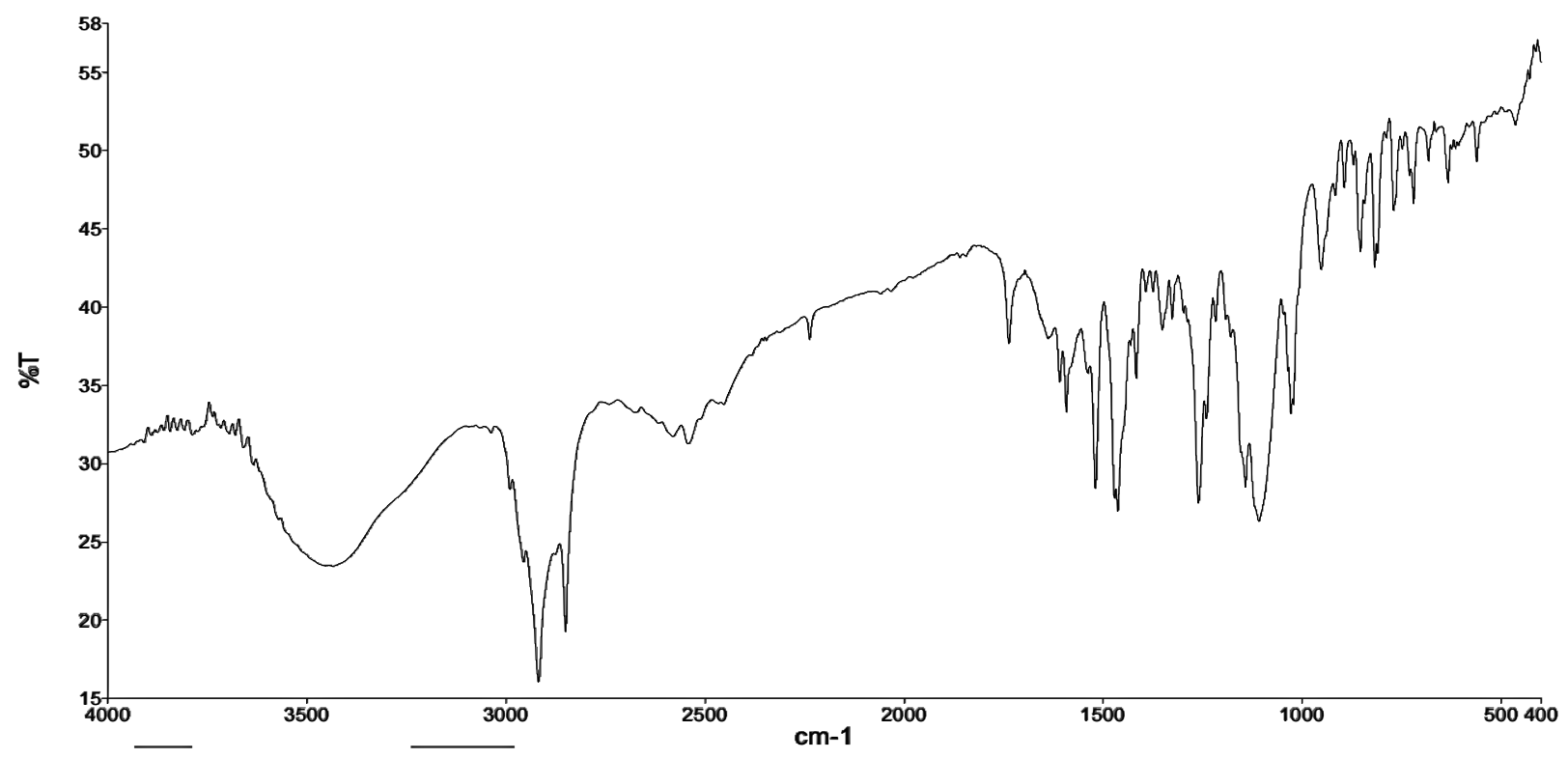

Fig. 4: FTIR spectrum of drug, stearic acid (SA) and PEG6000 mixture.

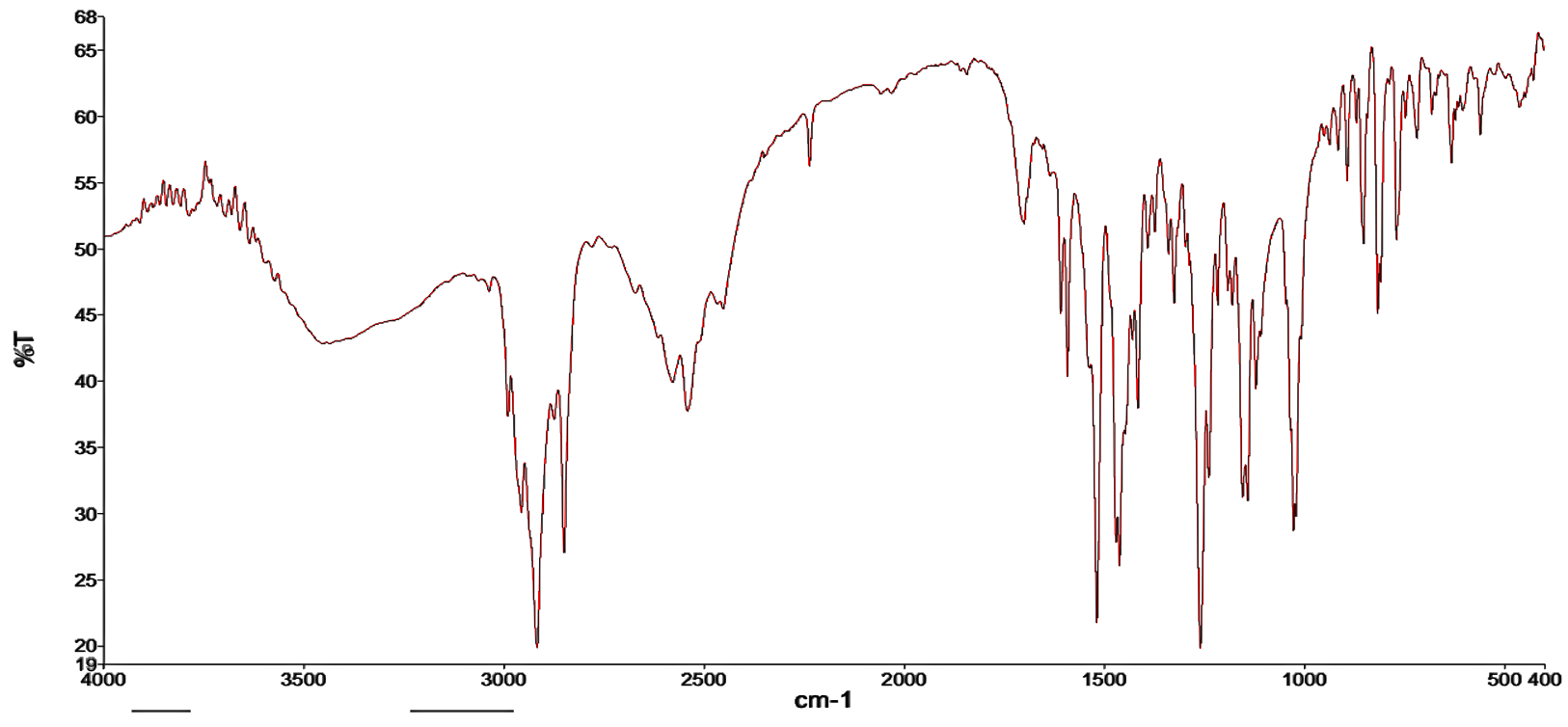

Fig. 5: FTIR spectrum of drug, Carnauba wax (CW), PEG 4000.

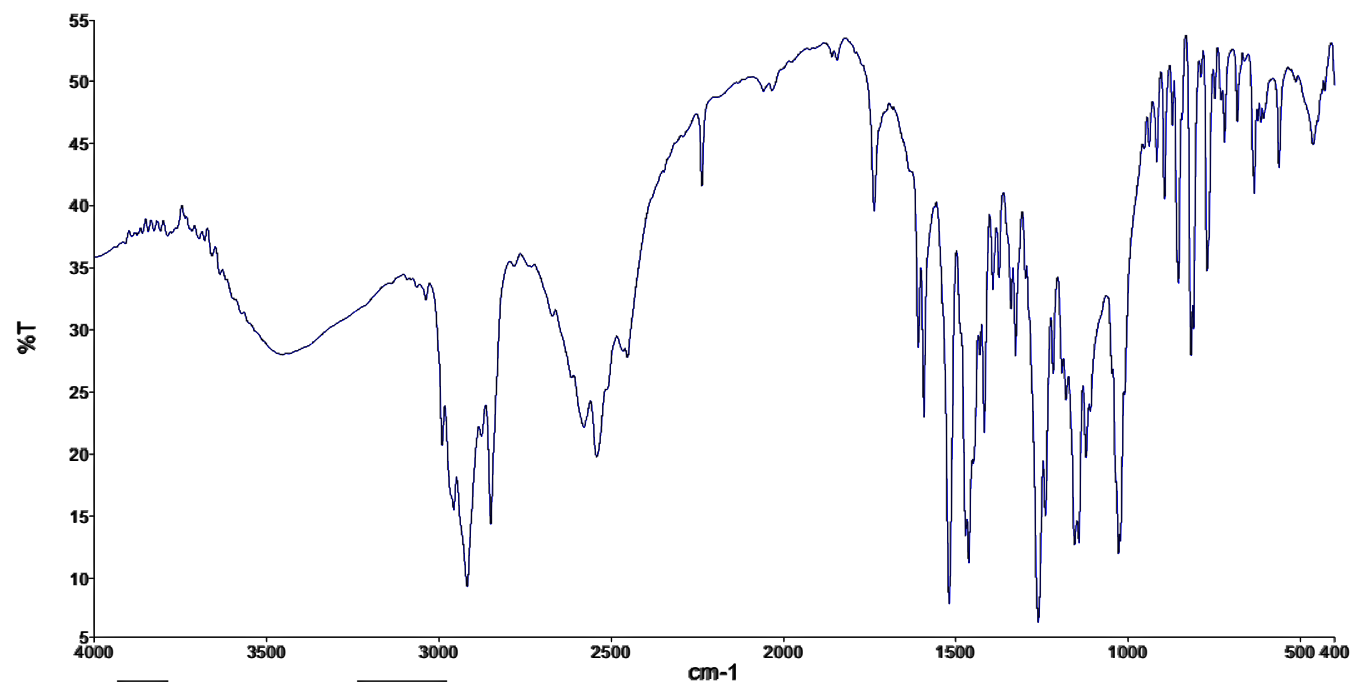

Fig. 6: FTIR spectrum of drug, Carnauba wax (CW), PEG 4000. 


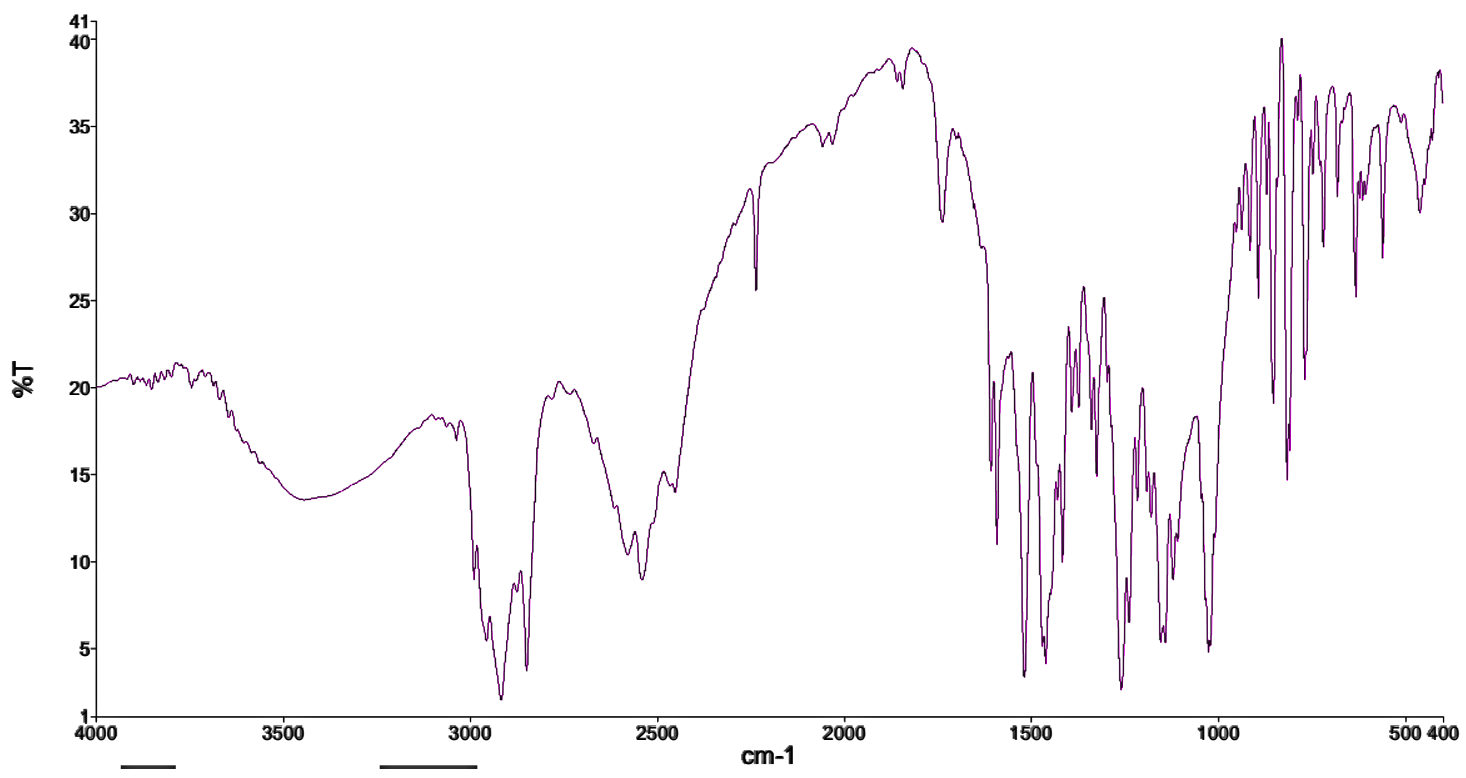

Fig. 7: FTIR spectrum of drug, bess wax (BW), PEG 6000.

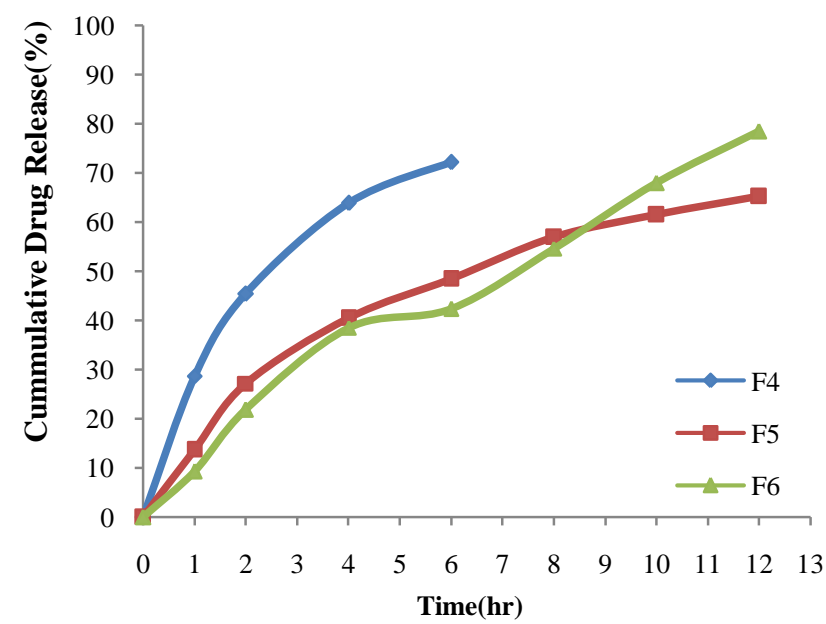

Fig. 8: Cumulative drug release profiles of formulations containing only waxes.

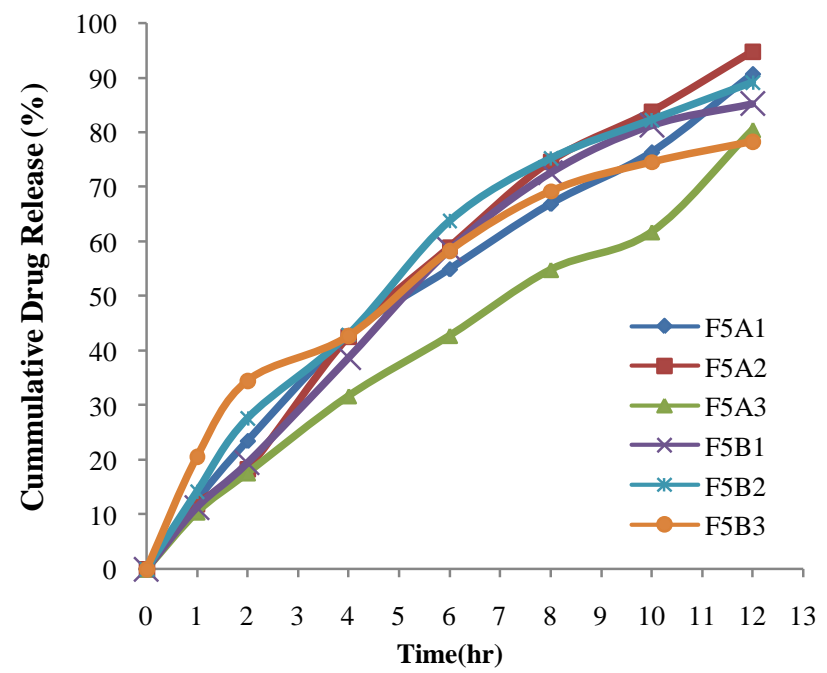

Fig. 10: Cumulative drug release profiles of formulations containing carnauba wax $(\mathrm{CW})$ along with PEG.

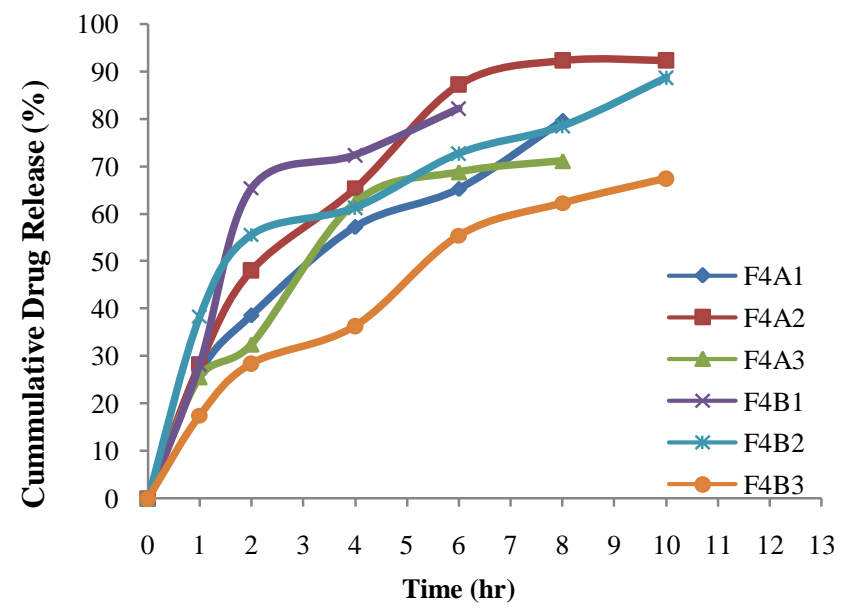

Fig. 9: Cumulative drug release profiles of formulations containing stearic acid (SA) along with PEG.

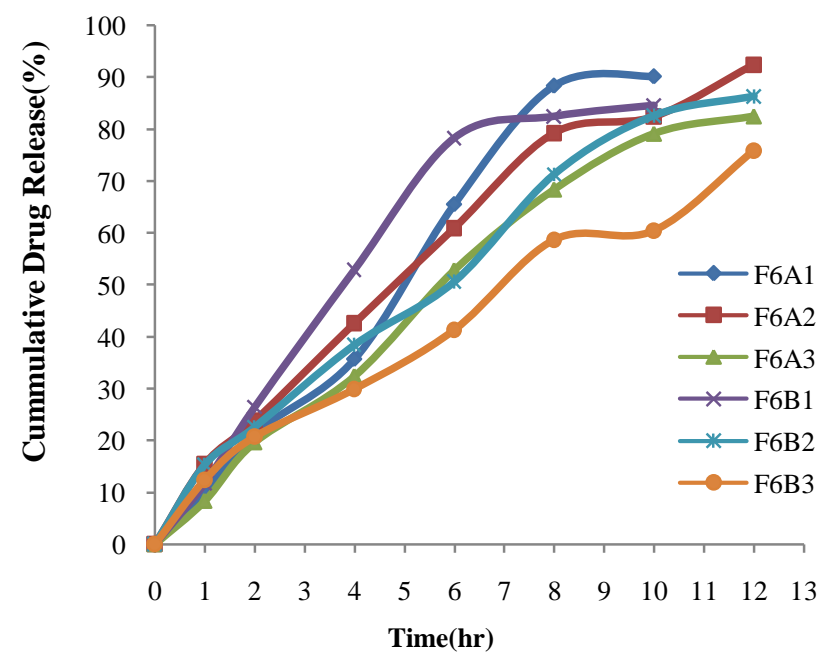

Fig. 11: Cumulative drug release profiles of formulations containing bess wax (BW) along with PEG. 


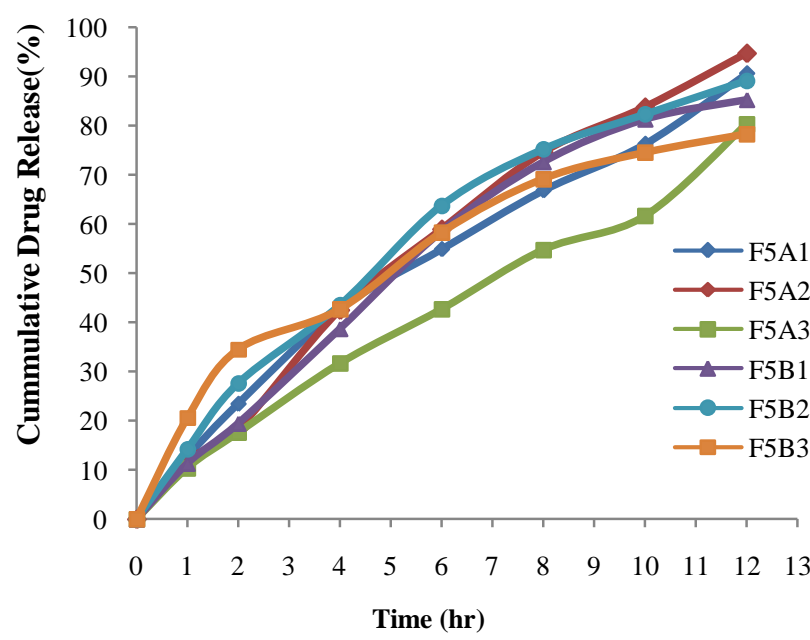

Fig. 12: Cumulative \%drug release vs time for optimized formulations of Carnauba wax.

\section{Evaluation of granular blend}

The angle of repose, bulk density, tapped density and compressibility index values of the granules are presented in Table 4.

Table 4: Evaluation of flow properties of three optimized formulations containing three different hydrophobic carriers

\begin{tabular}{cccc}
\hline Flow Property & F4A2 & F5A2 & F6A2 \\
\hline Angle of repose $\left(0^{0}\right)$ & 35.6 & 18.8 & 26 \\
Bulk density $\left(\mathrm{g} / \mathrm{cm}^{3}\right)$ & 0.49 & 0.61 & 0.57 \\
Tapped density $\left(\mathrm{g} / \mathrm{cm}^{3}\right)$ & 0.63 & 0.72 & 0.70 \\
Carr's index $(\%)$ & 22.22 & 15.2 & 18.57 \\
Hausner's ratio & 1.28 & 1.18 & 1.22 \\
\hline
\end{tabular}

The flowability of the granules is poor, this observation is attributable to the sticky nature of the waxes, resulting in interparticle cohesion. This effect was more severe with the stearic acid (SA) granulations, which did not flow easily during measurement of angle of repose. After admixing the granules, with microcrystalline cellulose prior to tableting and compression improved its flow properties. Systems granulated with carnauba wax were less sticky; hence some degree of flowability was achieved. The angle of repose for all the formulations is in the range of $18.8-35$. The value with stearic acid (SA) granules was found to be 35.6 which indicate fair flow properties. The angle of repose for carnauba wax $(\mathrm{CW})$ and bess wax $(\mathrm{BW})$ granules was found to be less than 30 which mean they have excellent flow properties. The carr's index was found to be 22.2 with stearic acid (SA), 15.2 with carnauba wax (CW) and 18.57 with bess wax (BW) granules. It infers that carnauba wax $(\mathrm{CW})$ granules have excellent flow properties while stearic acid (SA) and bess wax (BW) show fair flow properties. The granules are said to be free flowing when its hausner's ratio is less than 1.25. In the present work it is found that Hausner's ratio for stearic acid (SA) granules is 1.28 hence, it has poor flow properties while carnauba wax (CW) and bess wax (BW) show good flow properties. As a whole, on comparison of the three hydrophobic carriers used they can be

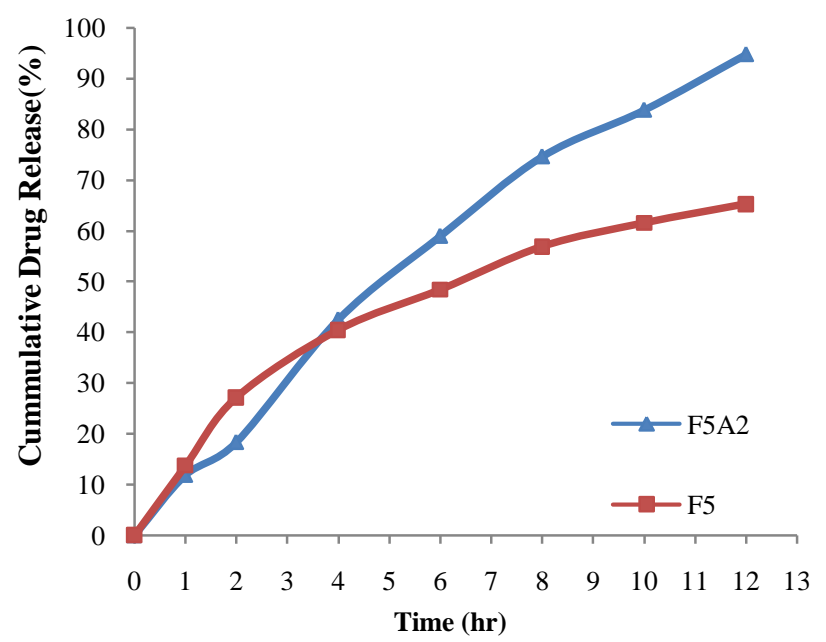

Fig. 13: Graph showing the drug release profiles of Carnauba wax formulations before and after adding PEG .

arranged in increasing order of their flow properties as stearic acid $(\mathrm{SA})<$ bess wax $(\mathrm{BW})<$ Carnauba wax $(\mathrm{CW})$.

\section{Evaluation of tablets}

Tablet 20 indicates the results of the various physicochemical tests (hardness, friability and drug content) performed on the tablet formulations. The hardness of the tablets produced by melt granulation technique was in the range of 4.3$5.7 \mathrm{Kg} / \mathrm{cm}^{2}$. All the formulations showed less than $1 \%$ friability which is within the prescribed limit. stearic acid (SA) formulations showed more loss when compared to others. According to IP, the percentage deviation permitted in the tablet weight variation is $7.5 \%$ and all the formulations were within this limit. The theoretical range of drug content given in IP is 90-110 $\%$ and the practical range was found to be $95.06-99.73 \%$. The stearic acid (SA ) formulations showed only $95 \%$ drug, this might be the loss due to its sticky nature and the rough tablet surfaces.

\section{Dissolution studies}

Formulations $\mathrm{F} 1$ to $\mathrm{F} 3$ were prepared using only waxes by melt granulation technique without using any other excipients. It was found that tablets were not intact and got dispersed within one hour after starting the dissolution in the medium. Even the minimum hardness is not achieved. Hence waxes in this concentration cannot be used alone to obtain a good product. Formulations F4 to F6 were prepared by a minor modification of the above formulas by incorporating micro crystalline cellulose which is a multipurpose ingredient. Microcrystalline cellulose can act as a direct compressible vehicle, filler to make the bulk volume and as a release enhancer. It was observed that the tablets prepared stayed intact and the hardness is also achieved. The in vitro drug release, when observed, showed that the waxes act as good retardants and hence, sustains the action. But it was found that the retardation effect is very high. Mainly, Carnauba wax (CW) retards the drug release to a higher extent rather than stearic acid 
(SA) and bess wax (BW) (approximately only 65\% drug is released after $12 \mathrm{~h}$ of dissolution). Hence, we can conclude that Carnauba wax $(\mathrm{CW})$ acts as a very good retardant. stearic acid (SA) does not prolong the action for $12 \mathrm{~h}, 72 \%$ of which got dissolved in $6 \mathrm{~h}$ and the tablets got dispersed and were not intact. When PEG (4000 and 6000) was included in the above formulations containing waxes in three different ratios according to the optimization process, it was found that drug release for all the formulations increased when compared to the formulations containing only waxes. However, the drug release increased only to some extent of polymer concentration. It was observed that as the concentration of the polymer increases, the drug release decreases. Hence, it needs to be incorporated in an optimized ration in proportion to the wax content. The formulations containing carnauba wax $(\mathrm{CW})$ showed good release with PEG than stearic acid (SA) and bess wax (BW) .The formulation, $\mathrm{F}^{2} \mathrm{~A}_{2}$ has shown a good release of $94.4 \%$ after $12 \mathrm{~h}$. All the carnauba wax $(\mathrm{CW})$ formulations exhibited the high drug release almost greater than $85 \%$ after $12 \mathrm{~h}$ which is nearly a very good increase from $65 \%$ release after $12 \mathrm{~h}$ with only waxes. Hence we can say that PEG acts as a channeling agent and decreased the tortousity of the matrix and increased the porosity of the matrix causing the drug to release slowly in a controlled manner for $12 \mathrm{~h}$. The formulations containing stearic acid (SA) nearly showed $92 \%$ release after $10 \mathrm{~h}$ but the problem with the usage of stearic acid (SA) was that it turns into hard flakes easily and in a very short period of time after melting and the lump formation becomes difficult. The granules prepared were also wet and waxy due to which it sticks to the die wall and the punch surfaces during punching. As a consequence, the drug content is decreased in all the formulations containing stearic acid (SA) and thereby the tablet is not staying intact for $12 \mathrm{~h}$. It was also observed that Drug release was found to be good with PEG 6000 than PEG 4000 in all the cases with stearic acid (SA), carnauba wax $(\mathrm{CW})$ and bess wax (BW).

Table 5: Evaluation of tablets of three optimized formulations containing different hydrophobic carrier.

\begin{tabular}{lccc}
\multicolumn{1}{c}{ Evaluation Parameter } & F4A2 & F5A2 & F6A2 \\
\hline Weight variation $(\mathrm{mg})$ & $170 \pm 3.5$ & $178 \pm 2.6$ & $176 \pm 3.4$ \\
Hardness $\left(\mathrm{Kg} / \mathrm{cm}^{2}\right)$ & $4.3 \pm 0.1$ & $5.2 \pm 0.3$ & $5.7 \pm 0.6$ \\
Friability $(\%)$ & 0.98 & 0.13 & 0.22 \\
Drug content $(\%)$ & $95.06 \pm 0.34$ & $99.73 \pm 0.77$ & $98.21 \pm 0.28$ \\
Thickness $(\mathrm{mm})$ & $2.5 \pm 0.04$ & $2.1 \pm 0.03$ & $1.9 \pm 0.2$ \\
\hline
\end{tabular}

\section{Drug release kinetics}

Knowledge of the drug release kinetics will provide understanding of the drug release mechanism. Values of the linear regression coefficients $(\mathrm{R})$ are presented in the tables 6-8.

Table 6: ' $R$ ' and ' $n$ 'values of Stearic acid formulations.

\begin{tabular}{lcccccc}
\hline & $\mathbf{F 4 A}_{\mathbf{1}}$ & $\mathbf{F 4 A}_{\mathbf{2}}$ & $\mathbf{F 4 A}_{\mathbf{3}}$ & $\mathbf{F 4 B}_{\mathbf{1}}$ & $\mathbf{F 4 B}_{\mathbf{2}}$ & $\mathbf{F 4 B}_{\mathbf{3}}$ \\
\hline Zero Order & 0.916 & 0.859 & 0.866 & 0.797 & 0.796 & 0.939 \\
First Order & 0.982 & 0.960 & 0.928 & 0.916 & 0.953 & 0.982 \\
Higuchi model & 0.996 & 0.976 & 0.966 & 0.936 & 0.960 & 0.984 \\
Peppas model & 0.993 & 0.967 & 0.946 & 0.830 & 0.969 & 0.984 \\
'n' Value & 0.52 & 0.52 & 0.54 & 0.558 & 0.33 & 0.59 \\
Hixon crowell & 0.987 & 0.933 & 0.893 & 0.838 & 0.972 & 0.976 \\
\hline
\end{tabular}

Table 7: 'R' and ' $n$ 'values of Carnauba wax formulations.

\begin{tabular}{lllllll}
\hline & $\mathbf{F 5 A}_{\mathbf{1}}$ & $\mathbf{F 5 A}_{\mathbf{2}}$ & $\mathbf{F 5 A}_{\mathbf{3}}$ & $\mathbf{F 5 B}_{\mathbf{1}}$ & $\mathbf{F 5 B}_{\mathbf{2}}$ & $\mathbf{F 5 B}_{\mathbf{3}}$ \\
Zero Order & 0.979 & 0.980 & 0.990 & 0.965 & 0.954 & 0.915 \\
First Order & 0.941 & 0.939 & 0.939 & 0.993 & 0.985 & 0.986 \\
Higuchi model & 0.973 & 0.958 & 0.948 & 0.976 & 0.960 & 0.992 \\
Peppas model & 0.995 & 0.989 & 0.997 & 0.989 & 0.990 & 0.985 \\
'n' Value & 0.777 & 0.877 & 0.804 & 0.741 & 0.857 & 0.535 \\
Hixon crowell & 0.977 & 0.987 & 0.962 & 0.982 & 0.998 & 0.981 \\
\hline
\end{tabular}

Table 8: 'R' and ' $\mathrm{n}$ 'values of Bess wax formulations.

\begin{tabular}{lcccccc}
\hline & $\mathbf{F 6 A}_{\mathbf{1}}$ & $\mathbf{F 6 A}_{\mathbf{2}}$ & $\mathbf{F 6 A}_{\mathbf{3}}$ & $\mathbf{F 6 B}_{\mathbf{1}}$ & $\mathbf{F 6 B}_{\mathbf{2}}$ & $\mathbf{F 6 B}_{\mathbf{3}}$ \\
Zero Order & 0.974 & 0.965 & 0.976 & 0.917 & 0.977 & 0.980 \\
First Order & 0.938 & 0.971 & 0.985 & 0.960 & 0.975 & 0.965 \\
Higuchi model & 0.913 & 0.97 & 0.948 & 0.944 & 0.962 & 0.957 \\
Peppas model & 0.988 & 0.992 & 0.988 & 0.964 & 0.991 & 0.989 \\
'n' Value & 0.99 & 0.752 & 0.932 & 0.88 & 0.73 & 0.714 \\
Hixon crowell & 0.959 & 0.988 & 0.988 & 0.932 & 0.983 & 0.973 \\
\hline
\end{tabular}

\section{CONCLUSION}

From the experimental studies it can be concluded that, the sustained release matrix tablets can be prepared using hydrophobic carriers which act as very good retardants of the drug. PEG can be used as a channeling agent in waxy matrices to regulate the release of the drug. The IR spectral analysis revealed that there are no interactions between drug and the polymers and are compatible with other.

The granulations when evaluated for their flow properties, showed beneficial flow properties. The formulated tablets are in conformation with the IP limits when evaluated for its physicochemical properties.

The in vitro studies revealed that the formulation containing only waxes F4, F5, F6 released only $78.46 \%, 65.24 \%$, $72.11 \%$ respectively. Among all the waxes used, carnauba wax (CW) acts as best retardant of drug release and release only $65.24 \%$ after $12 \mathrm{~h}$. With the addition of PEG, the drug release increased as it acts as a channeling agent and almost $90 \%$ reached after $12 \mathrm{~h}$. Hence, it can be concluded that waxy matrices acts as very good retardants and to modulate the release, we can use channeling agents like PEG. Among the two grades of PEG used 4000 and 6000, PEG 6000 increases the drug release to a greater extent than PEG 4000.

\section{CONFLICT OF INTERESTS}

\section{Declared None}

\section{ACKNOWLEDGEMENT}

The authors would like to thank Department of Pharmaceutics, GITAM Institute of Pharmacy and chemistry for providing facility and assistance during FTIR studies.

\section{REFERENCES}

Chugh I, Seth N, Rana A.C, Guptha S. Oral sustained release drug delivery system: An overview. International research Journal of pharmacy, 2012; 3 (5): 57-62.

Yamada T, Onishi H, Machida Y. Sustained release ketoprofen microparticles with ethylcellulose and carboxymethylethylcellulose. J Control Release, 2001; 75(3): 271-282. 
Bhagwat DA, Kawtikwar PS, Sakarkar DM. Sustained release matrices of verapamil $\mathrm{HCl}$ using glyceryl monosterate and stearic acid. Res J Pharm Tech, 2008;1: 405-09.

Vikas M, Kalpana N, Shailendra Kumar S, Dina Nath M. Comparative release profile of sustained release matrix tablets of verapamil $\mathrm{HCl}$. Int J Pharm Investig, 2013; 3(1): 60-65.

Senthil K , Anand P, Sravanakumar M, Thirumurthy R. Formulation and evaluation of diltiazem hydrochloride extended release tablet by melt granulation technology. Int. J. Pharm \& Ind. Res, 2011; 1(1): $36-42$.

Durgacharan A, Pravin S, Dinesh M. Sustained Release Matrices of Verapamil $\mathrm{HCl}$ Using Glyceryl Monosterate and Stearic Acid. Research J.Pharm and Tech, 2008; 1(4):405-409.

Mobeen M, Sathish A, Prakash G , Sarika M , Banu T, Ramakrishna R. Formulation and evaluation of mucoadhesive microspheres of pioglitazone hydrochloride using a natural polymer. International Journal of Pharma Sciences and Research, 2015; 6(4):723737.

Lohithasu D, Madhu Latha AVS, Midhun Kumar D, Girish P. Formulation and evaluation of Cordia dichotoma fruit mucilage as matrix forming agent for sustained release of propranolol hydrochloride. Int $\mathrm{J}$ Pharm, 2015; 5(2): 512-517.

Narashimhan B, Mallapragada SK, Peppas NA. 1999. Release kinetics, data interpretation. in: Encyclopedia of Controlled Drug Delivery. Eds., p. 921, John Wiley and Sons, Inc, New York.
Silvina A, Bravo M., Lamas C, Claudio J. In-vitro studies of diclofenac sodium controlled-release from biopolymeric hydrophilic matrices. J Pharm Pharm Sci, 2002; 5:213-219.

Higuchi T. Rate of release of medicaments from ointment bases containing drugs in suspension. J Pharm Sci,1961; 50:874-875.

Grassi M, Grassi G. Mathematical modelling and controlled drug delivery: matrix systems. Curr Drug Deliv, 2005; 2: 97-116.

Korsmeyer RW, Gurny R, Doelker EM, Buri P, Peppas NA. Mechanism of solute release from porous hydrophilic polymers. Int $\mathrm{J}$ Pharm, 1983; 15:25-35.

Ritger PL, Peppas NA. A simple equation for description of solute release, II: Fickian and anomalous release from swellable devices. J Control Release, 1987;5:37-42.

\section{How to cite this article:}

Sarada A, Lohithasu D, Pratyusha PV. Development of Hydrophobic Carriers based tablets for Sustained Release of Verapamil. J App Pharm Sci, 2015; 5 (12): 125-134. 